\title{
Earthquake damage to Christian basilica churches: the application of an expert system for the preliminary in-plane design of stone masonry piers
}

\author{
G. C. Manos, L. Kotoulas, O. Felekidou, S. Vaccaro \\ \& E. Kozikopoulos \\ Laboratory of Strength of Materials and Structures, \\ Department of Civil Engineering, \\ Aristotle University of Thessaloniki, Greece
}

\begin{abstract}
This paper summarizes observations and conclusions from a series of investigations on the seismic performance of stone masonry Christian basilica churches. A considerable number of these churches develops structural damage to the masonry walls-piers that arises from the amplitude of the gravitational and seismic actions combined with the deformability of the foundation. This traditional "old-type" construction for Christian churches still exists in several regions of the Mediterranean Basin, apart from Greece, despite the considerable seismic hazard that these regions are exposed to. An expert system was developed, which utilizes the basic geometric and material characteristics of a given masonry pier together with the in-plane stress resultant demands in a cross section, such as the axial force $\left(N_{y}\right)$ the bending moment $\left(M_{y}\right)$ and the shear force $\left(Q_{y}\right)$, in order to check the performance of such a pier. This is done by comparing the demands posed by these stress resultants with the corresponding capacities as they are predicted by the provisions of Euro-code 6 or from relevant empirical formulae. This is done by considering either the in-plane flexural or the in-plane shear capacity. This expert system is applied to typical basilica churches damaged by the recent 2014 Kefalonia earthquake in order to demonstrate its usefulness in the evaluation process of either the expected or the observed earthquake performance of this type of heritage structure.

Keywords: Christian basilica churches, stone masonry, expert system, predicted earthquake performance, evaluation of observed performance.
\end{abstract}




\section{Introduction}

During the last thirty years, various parts of Greece have been subjected to a number of damaging earthquakes ranging from $\mathrm{Ms}=5.2$ to $\mathrm{Ms}=7.2$ on the Richter scale. Some of these events, not necessarily the most intense, occurred near urban areas (Manos [1] and [2]). One of the most demanding tasks for counteracting the consequences of all these seismic events was the effort to ensure the structural integrity of old churches, that were built in periods ranging from 400 A.D. till today; in many cases they sustained considerable damage. Selected results and summary observations of the seismic behavior of a specific type of structural system are presented by Manos et al. [3-5]. This system is utilized in many churches belonging to the so called basilicas. This structural system is one of the oldest structural forms and it is frequently utilized for Greek Christian churches with a number of variations in plan and height. The "basilica" structural system is of rectangular shape, formed by the peripheral walls; a semi-cylindrical apse is usually part of the East wall, whereas the interior is divided into a number of naves by longitudinal colonnades of various dimensions and shapes (as shown in figure 1(a)). The roofing system is mainly in the longitudinal direction; this roofing system at the central nave usually rises at a higher level than that of the side-naves; in this sense, it can be seen as an elevated extension of the interior colonnades. On the contrary, the roofing system that covers the side naves is partially supported on the peripheral walls and is usually lower than the roof of the central nave (figure 1(b)). In some instances, this structural type takes the simplest form of one nave with no internal separations. This is also the form of rectangular old age masonry buildings with strong peripheral walls and weak internal separations.

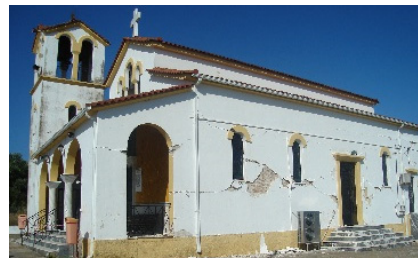

Patras, Greece earthquake 2008

(a)

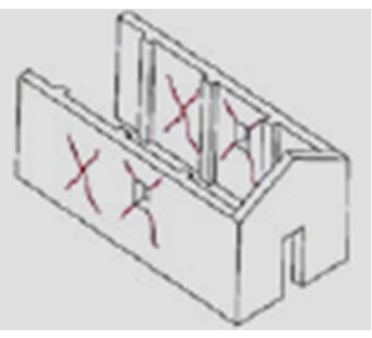

Kefalonia, Greece earthquake 2014

(b)

Figure 1: Typical damage patterns of longitudinal walls.

\section{Common forms of observed damage}

When such structural formations are subjected to horizontal earthquake forces the longitudinal and transverse walls represent the main structural elements that resist these forces [6]. Despite the fact that the total structural dynamic response is quite complex it is convenient to simplify this response for each one of these main resisting structural elements by decoupling it to in-plane and out-of-plane response 
that leads to a corresponding state of stress which acts together with the state of stress due to the gravitational forces. When the state of stress due the earthquake forces keeps increasing certain in-plane and out of plane limit strength values are reached that lead to corresponding modes of failure (figures 1, 2 and 3).

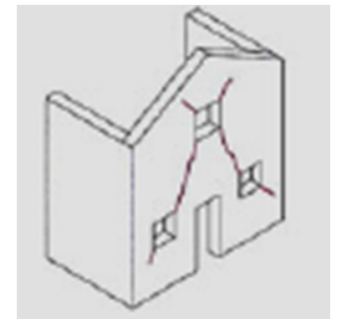

Typical in-plane damage of transverse walls

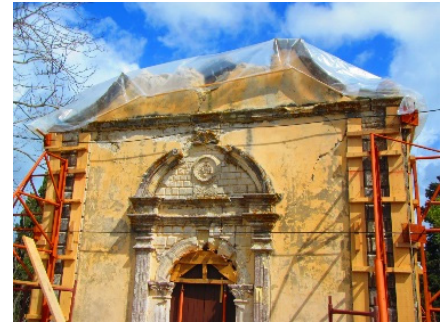

Kefalonia, Greece

earthquake 2014

Figure 2: Typical in-plane damage patterns for transverse walls.

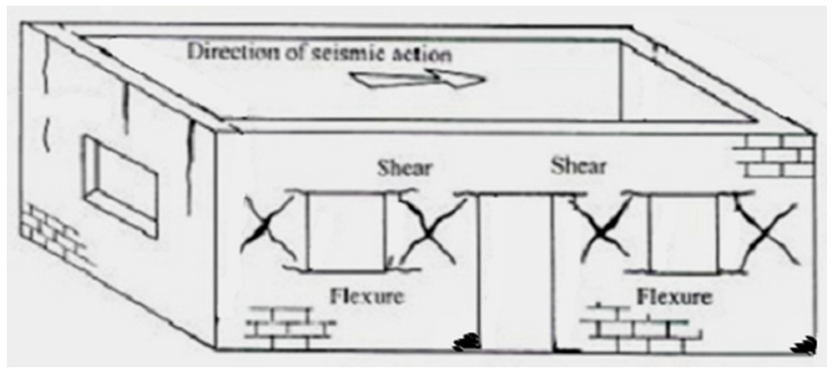

Figure 3: Typical in-plane damage patterns.

\section{Single masonry pier simplification}

Figures 1, 2 and 3 depict such typical in-plane damage patterns for longitudinal and transverse masonry walls. Each one of the in-plane damage patterns that develops in either the longitudinal or the transverse walls arises from the fact that at a certain location the state of stress resulting from combination of the gravitational loads (Vgr) and the earthquake forces (Heq), leads to a demand that exceeds the capacity at this location. The demands that arise at each location can be found by various simple or complex methods of numerical approximations and is not part of the current study. In order to simplify the process the expert systems assumes that each longitudinal and transverse wall is on its own by being composed of various vertical parts (piers) that together with the openings form each wall as a whole (figures 1 and 3). These piers usually form the weakest part of the structural. As was shown previously by figures 1 to 3 , these piers are the locations where the most severe structural damage usually concentrates. 
Aiming at simplification and following the above rational the expert system at the moment provides checks for the in-plane behaviour of simple individual piers as will be explained in the following. This expert system at the current state of development does not extend the checks to the out-of-plane behaviour of each pier. Moreover, the influence of the connections between the longitudinal and the transverse walls, although of importance, which results in significant deviations from this simple pier representation, is not yet addressed by this expert system.

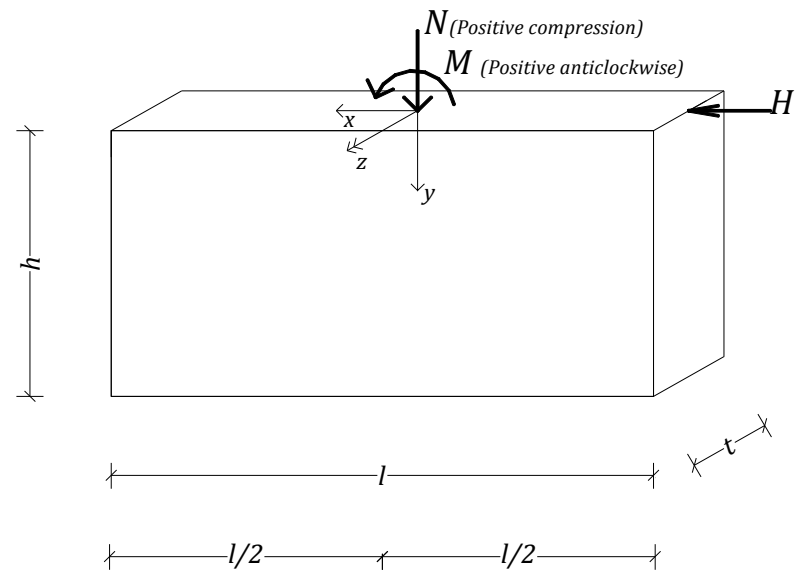

Figure 4: $\quad$ Single masonry pier being stresses in its upper boundary.

Consequently, each one of the piers is considered as being stressed in-plane mainly in their upper horizontal boundary and is being supported at their lower horizontal boundary (as shown in figure 4). Figure 4 depicts the geometry of such a masonry pier together with the in-plane loads $(\boldsymbol{N}, \boldsymbol{H}, \boldsymbol{M})$ acting on its upper boundary. The stress resultants $\boldsymbol{N}_{\boldsymbol{y}}, \boldsymbol{Q}_{\boldsymbol{y}}, \boldsymbol{M}_{\boldsymbol{y}}$ at a horizontal cross section located at a distance y from the top horizontal boundary of the pier are given below:

$$
M_{y}=M+H y, N_{y}=M+1 t \rho y, Q_{y}=H
$$

where $\rho$ is the specific gravity of the wall, 1 and $t$ are the geometrical dimension of the pier as shown in figure 4 . The calculation of the normal stress at this horizontal cross section is carried out as follows:

\section{Basic features of the expert system}

The distribution of axial stress $\left(\sigma_{\mathrm{n}}\right)$ normal to a bed joint with thickness equal to the pier thickness that develops at this horizontal section is assumed to be one of the following four simple cases depicted in figures 5(a) to 5(d), which are incorporated in many design provisions. The expert system chooses which of these four cases of normal stress distribution develops based on the geometry, the loads and the masonry compressive and tensile strength values, $f_{k d}$ and $f_{x k l d}$ respectively. These strength values as well as the checks being performed are based on the 
provisions of Eurocode 6 [7]; however, provisions from other codes can be easily incorporated. Together with the normal stress distribution, the length of the compressive zone $\left(\mathbf{l}_{\mathrm{c}}\right)$ is also calculated as well as the value of the average normal stress $\left(\sigma_{n}\right)$, which is assumed to act in this compressive zone as depicted in figures $5(\mathrm{a})$ to $5(\mathrm{~d})$. Use is made of both the compressive zone length and the average normal stress value for calculating next the masonry shear strength (see equations (2) to (4)).

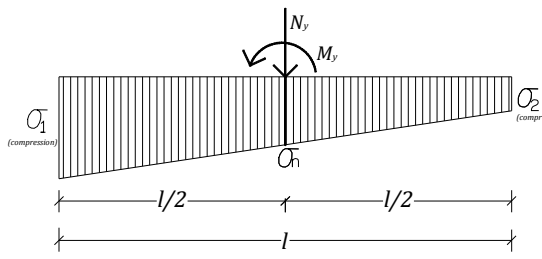

a. Case 1:

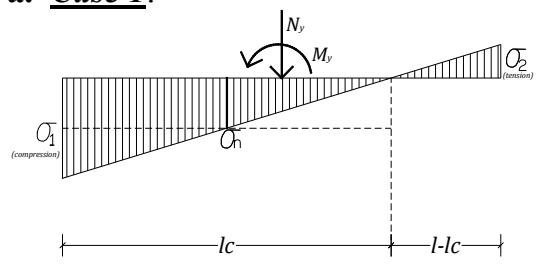

b. Case 2:

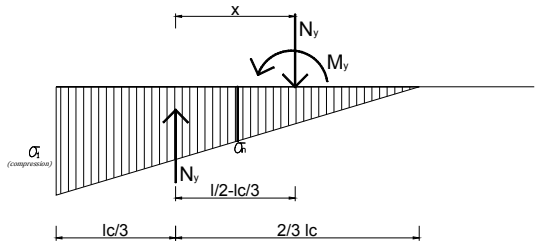

c. Case 3:

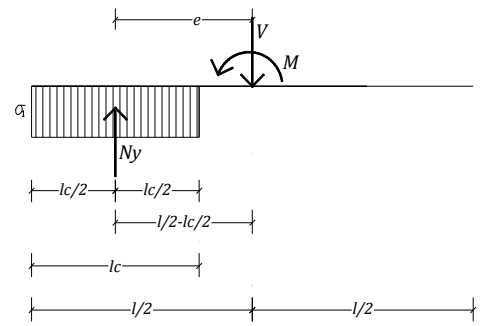

d. Case 4:
The normal stress distribution is compressive along all the length of the pier:

$$
\sigma_{1} \geq 0 \quad \text { and } \sigma_{2} \geq 0
$$

The largest normal stress value must be smaller than the masonry compressive strength $f_{k d}$

There is tension at the right zone of the cross section with stress $\sigma_{2}$ lower than the tensile limit stress $f_{x k l d}$; consequently, the tensile zone is assumed being active:

$$
\begin{array}{r}
\sigma_{1}>0 ; \sigma_{2}<0 ;\left|\sigma_{2}\right| \leq f_{x k 1 d} \\
\text { and } \sigma_{1}<f_{k d}
\end{array}
$$

There is tension at the right fiber of the cross section, larger than the tensile limit stress $f_{x k l d}$; consequently, the tensile zone is assumed being inactive:

$$
\begin{array}{r}
\sigma_{1}>0 ; \sigma_{2}<0 ;\left|\sigma_{2}\right|>f_{x k 1 d} \\
\text { and } \sigma_{1}<f_{k d}
\end{array}
$$

The tensile zone remains inactive but the compressive zone becomes narrower than before (towards developing flexural mode of failure):

$$
\begin{array}{r}
\sigma_{1}>0 ; \sigma_{2}<0 ;\left|\sigma_{2}\right| \geq f_{x k 1 d} \\
\text { and } e=\frac{M_{y}}{N_{y} l} \geq 0,45
\end{array}
$$

Figure 5: Normal to the bed-joint axial stress distribution patterns. 


\subsection{Predicting the masonry sliding shear strength}

Use is again made here of the provisions of Eurocode 6 [7]. For the masonry pier which is studied here the shear strength of the masonry $\left(f_{v k}\right)$ is the minimum value of the following:

$$
f_{v k}=f_{v k 0}+0.4 \sigma_{n}
$$

where $\sigma_{\mathrm{n}}$ is the value of the average normal stress, $f_{\mathrm{vk} 0}$ the shear strength of the masonry for zero normal stress that is specified by the provisions of Eurocode 6 [7].

$$
f_{v k}<0.065 f_{b}
$$

where $f_{b}$ is the compressive strength of the masonry unit.

$$
f_{v k}<f_{v k l i m}
$$

where $f_{\text {vklim }}$ is the upper shear strength of the masonry, as it is specified by the national appendix of each member state.

The developed expert system incorporates all these provision together with the calculation of the average normal stress $\left(\sigma_{n}\right)$, as explained before. In this way, the value of the masonry shear strength for the masonry pier in question can be obtained.

\subsection{Predicting the masonry sliding diagonal tension strength}

This is done based on the following formula (Eq. (5)) given by Turnsek and Cacovic [8],Bernardini et al. [9] and Tomaževič [10]. It is assumed that the tensile strength of the masonry $\sigma_{t}=f_{x k 1}$ depends on the maximum average shear stress $\tau_{\text {max }}$ of a horizontal section of the masonry pier and on the average compressive stress $\sigma_{d}=\frac{N}{A}$ that develops in the same location where A the area of this section and $\mathrm{N}$ the compressive load.

$$
\sigma_{t}=f_{x k 1}=\sqrt{\left(\sigma_{d} / 2\right)^{2}+\left(b \tau_{\max }\right)^{2}}-\sigma_{d} / 2
$$

where $b$ represents the shear stress distribution factor, which is related to the stress distribution on the section and the slenderness ratio of the wall. It can be assumed that $b=\frac{h}{l}$, where $h$ is the height and $\mathbf{I}$ is the length of the pier. In this case $b=1.5$ is the upper limit value and $b=1$ is the lower limit value. From the above relationship the value of $\tau_{\max }$ can be obtained based on the values of $\sigma_{t}=f_{x k 1}$ and $\sigma_{d}$ :

$$
\tau_{\max }=\frac{f_{x k 1}}{b} \sqrt{f_{x k 1}+\sigma_{d}}
$$

\subsection{Predicting the bearing capacity and the expected mode of failure for a masonry pier}

The following steps are necessary for examining the expected performance of a given unreinforced masonry pier in terms of bearing capacity and expected mode of failure. 
1. The basis of such a prediction is to include in the expert system the most common modes of failure that such a structural element can develop under the inplane loads shown in figure 4 . Because the focus of this study are the modes of failure that are due mainly to the seismic actions the expert system is built with checks that try to identify the development of the following modes of failure: a) The flexural mode of failure (figure 8(a)). This is done by assessing the distribution of the normal stress at a horizontal cross section, as explained before (figures 5(a) to 5(d)). At the same time the maximum compressive stress is also checked which must attain values below the limit compressive strength of the masonry $\left(f_{k d}\right)$. If not, flexural failure is predicted by the expert system. b) The sliding mode of failure of a horizontal cross-section located either at the bottom or at mid-height of the pier. In doing so the simple Mohr-Coulomb friction is assumed as it is expressed by the provisions of Eurocode 6 (Eq. (2) [7]), for unreinforced masonry, as presented before. The shear/sliding capacity in this case is found based on the masonry sliding shear strength, presented before, and on the compressive zone length $\left(\boldsymbol{l}_{\mathrm{c}}\right.$ ) found by the expert system (see figures $5(\mathrm{a})$ to $5(\mathrm{~d})$ ). c) The shear/diagonal mode of failure; this is calculated from the combined state of stress for the pier, as outlined before. The expert system predicts this shear/diagonal tension capacity based on the procedure that calculates the maximum shear/diagonal tension stress (Eq. (6)).

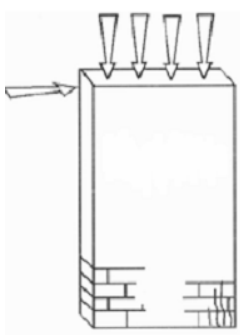

(a)

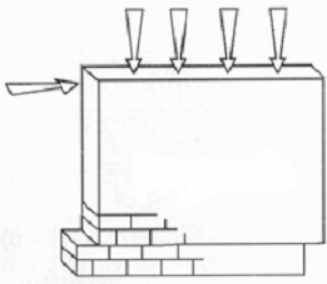

(b)

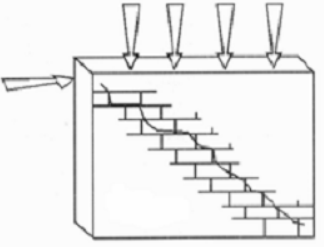

(c)

Figure 6: Typical in-plane failure modes, considered by the expert system, for individual piers subjected to gravitational forces and in-plane seismic actions: (a) flexural; (b) shear/sliding and (c) shear/diagonal tension.

2. The expert system can be utilized for a given pier and for a given load combination $(\boldsymbol{N}, \boldsymbol{M}, \boldsymbol{H})$ in order to perform the necessary checks at any given horizontal cross section of the pier located at a distance y from the top horizontal boundary from the top. This is done in order to provide the answer whether the combination of the demands $\boldsymbol{N}_{\boldsymbol{y}}, \boldsymbol{M}_{\boldsymbol{y}}$ and $\boldsymbol{Q}_{\boldsymbol{y}}$ exceeds or not the flexural or shear capacity (sliding or diagonal tension) of the pier at this cross section. The compressive capacity of the pier is not checked. In doing so, the expert system predicts at the same time which capacity is exceeded first, either the flexural or the shear (sliding or diagonal tension), thus predicting the expected mode of failure. 
3. An alternative way in which this expert systems can be utilized is the following. For a given geometry, material properties and load combination $N, \boldsymbol{M}, \boldsymbol{H}$ it is sometimes useful to consider what will be the limit bearing seismic capacity $\left(\boldsymbol{H}_{\text {lim }}\right)$ of this pier. This is done by the expert system through a procedure that the initial seismic load is gradually increased in a stepwise manner. This increase results in a corresponding increase for the demands $\boldsymbol{M}_{\boldsymbol{y}}$ and $\boldsymbol{Q}_{\boldsymbol{y}}$ at any given horizontal cross section of the pier located at a distance y from the top horizontal boundary from the top, whereas $\boldsymbol{N}_{\boldsymbol{y}}$ remains constant. At any step, the expert system compares these demands to the shear and flexural capacity of the pier. In case either of these demands exceeds the relevant capacity the expert system stops providing at the same time in this way both the predicted in this way value of the limit bearing seismic capacity of the pier $\left(\boldsymbol{H}_{\text {lim }}\right)$ and the corresponding mode of failure.

The basic geometric and material characteristics together with the load conditions of a given masonry pier are known input values. Based on such input information, which is provided through a user friendly interactive way (figure 7), the expert system calculate the in plane performance of the pier, as described before. This expert system is being developed using the language VBA of excel.

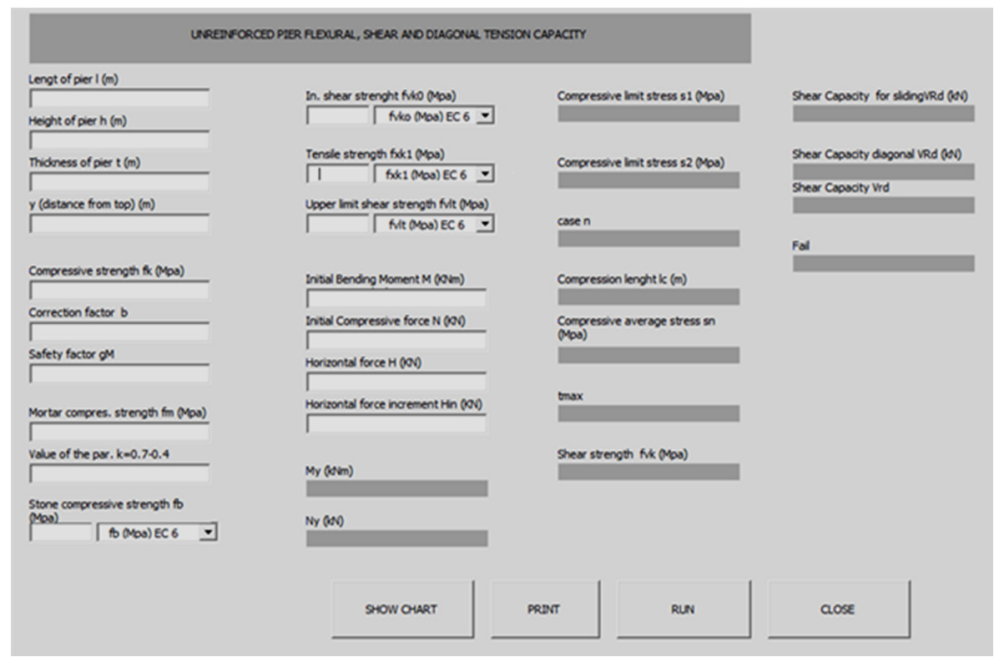

Figure 7: Input-output interface of the expert system.

\section{Results from the application of the expert system}

The expert system is applied to check the performance of the stone masonry piers at the base of the transverse walls of two churches in Kefalonia, Greece, damaged during the earthquake sequence of January-February 2015 (Manos and Kozikopoulos [11]). These basilica churches are Panagia at Chavriata and Agia Marina at Soullaroi. Both churches sustained heavy structural damage depicted in figures $8(\mathrm{a})$ and $8(\mathrm{~b})$, respectively. The dimensions in meters are 
also indicated in these figures. The examined by the expert system piers are the ones at the West transverse wall (façade) between the door at and the North and South walls (see figures 8(a) and 8(b)). The base shear forces for the two churches were obtained through a dynamic spectral analysis with an acceleration spectrum the one derived from the ground acceleration recorded by an accelerograph located at the floor of an old school at Chavriata. The distance between the Agia Marina at Soullaroi and Chavriata is less than two kilometers. Consequently, the same input response spectrum ( $\mathrm{q}=1.5)$ was used for both churches (4 and 5 first eigen-modes for Ag. Marina and Panagia, respectively). Two types of soil were examined by introducing two-node links at the soil-foundation interface; hard soil conditions were assumed with link axial stiffness equal to $109 \mathrm{KN} / \mathrm{mm}$ and soft soil conditions when this link axial stiffness value was equal to $24.5 \mathrm{KN} / \mathrm{mm}$.

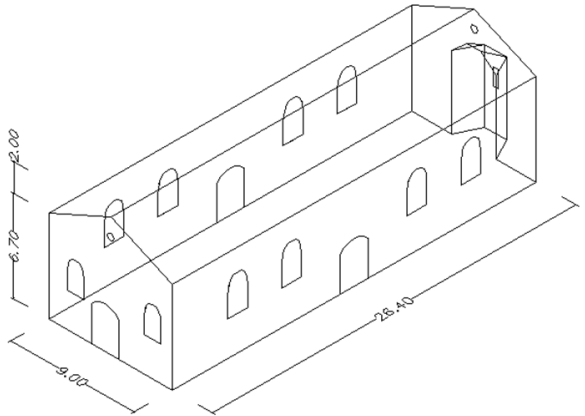

(a)

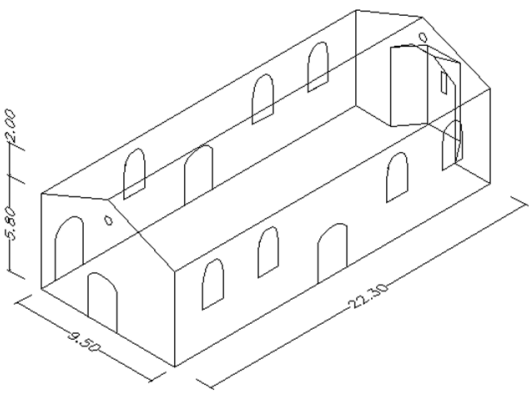

(b)

Figure 8: (a) The Church of Panagia at Chavriata and (b) the Church of Agia Marina at Soullaroi.

The shear demands when the seismic forces act in the transverse (y-y) NorthSouth direction and thus subject the relatively short East or West masonry walls of these churches to in-plane seismic actions are listed in table 1. The listed values are the base shear demands in this direction for the whole church as well as the shear demand $(\mathrm{Q})$ for the examined here masonry piers.

Table 2 lists the assumed mechanical characteristics for the stone masonry in terms of compressive, shear and tensile strength values. $f_{v k o}$ is the shear strength of the stone masonry when the normal stress is zero; fvko was assumed to be equal

Table 1: $\quad$ Shear demands based on the Chavriata response spectra in the EastWest (y-y) transverse direction.

\begin{tabular}{|c|c|c|}
\hline Name of church & $\begin{array}{c}\text { Base shear }(\mathrm{KN}) \text { for the } \\
\text { whole church, hard soil }\end{array}$ & $\begin{array}{c}\text { Shear Q }(\mathrm{KN}) \text { for the } \\
\text { studied pier }(\mathbf{l}, \mathrm{t}), \text { soft soil }\end{array}$ \\
\hline Agia Marina, Soullaroi & 8828 & $1351(4156 \mathrm{~mm} \times 750 \mathrm{~mm})$ \\
\hline Panagia, Chavriata & 16308 & $2330(3600 \mathrm{~mm} \times 750 \mathrm{~mm})$ \\
\hline
\end{tabular}


Table 2: $\quad$ The assumed mechanical characteristics for the stone masonry.

\begin{tabular}{|l|c|c|c|}
\hline Limit values & $\begin{array}{c}\text { Compressive } \\
\text { strength } f_{k} \\
(\mathrm{MPa})\end{array}$ & $\begin{array}{c}\text { Shear } \\
\text { strength } f_{\text {vko }} \\
(\mathrm{MPa})\end{array}$ & $\begin{array}{c}\text { Axial tensile strength } \\
\text { normal/parallel to bed-joint } \\
f_{x k 1} / f_{x k 2}(\mathrm{MPa})\end{array}$ \\
\hline 3,50 & 0,16 & $0,15 / 0,6$ \\
\hline
\end{tabular}

to $0.160 \mathrm{~N} / \mathrm{mm}^{2}$. The values listed in table 4 were assumed to be valid for both churches based on relevant strength values employed in similar studies [1, 3-5, $11,12]$. However, the necessity to quantify such limit value through tests based on in-situ samples must once more be underlined.

Figures 9(a) and 9(b) depict the un-plane tensile axial stresses distribution normal to bed-joints together with values of the ratio in-plane flexural capacity / demand $(R \sigma)$. As can be seen these values are much smaller than 1 , for both the right and left masonry pier of this West side near the door, indicating in-plane flexural failure (Manos and Kozikipoulos [11]).

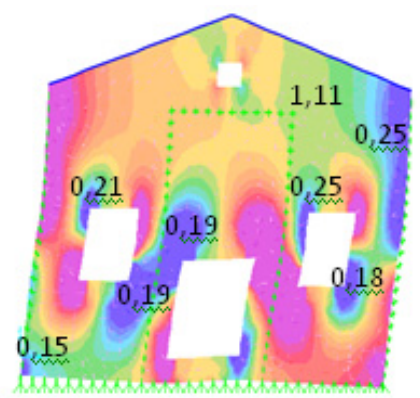

(a)

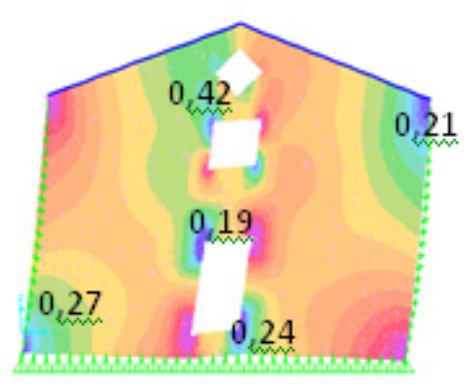

(b)

Figure 9: In-plane tensile axial stresses distribution normal to bed-joints. Values of $\mathrm{R} \sigma=$ in-plane flexural capacity/demand: (a) the Church of Panagia at Chavriata and (b) the Church of Agia Marina at Soullaroi.

Similarly, figures 10(a) and 10(b) depict the in-plane shear stress distribution at the bed-joints together with values of the in-plane shear capacity/demand ratio $(\mathrm{R} \tau)$. Again, it can be seen in certain locations these values are much smaller than 1 , for both the right and left masonry pier of this West side near the door, indicating in-plane shear failure. In this type of evaluation the demands and capacities are found at local areas of the masonry walls where the relevant stress demands are maximized. Figures 11(a) and 11(b) depict the damage masonry West walls of both churches. As can be seen, the damage predictions are in agreement with the observed performance. 


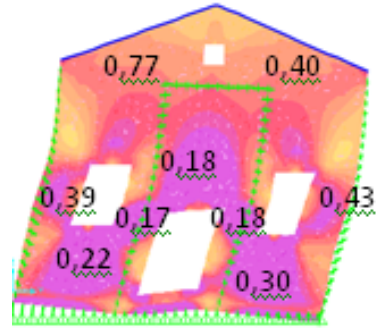

(a)

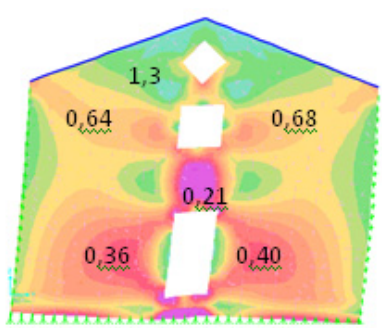

(b)

Figure 10: In-plane shear stress distribution at the bed-joints. Values of $\mathrm{R} \tau=$ inplane shear capacity/demand: (a) the Church of Panagia at Chavriata and (b) the Church of Agia Marina at Soullaroi.

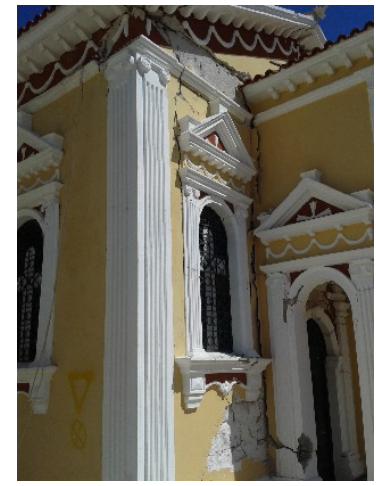

(a)

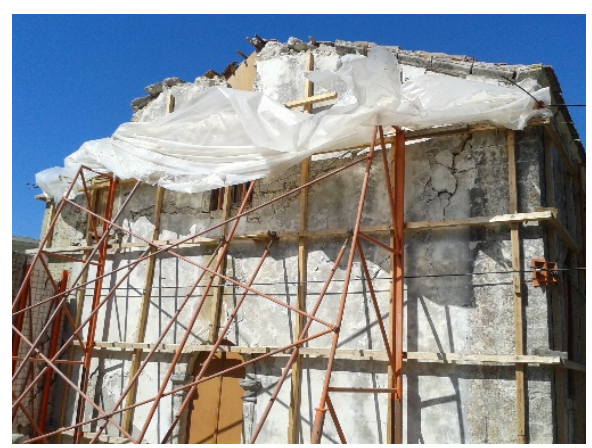

(b)

(b)

Figure 11: Observed damage from the 3rd February 2015 strongest aftershock: (a) the Church of Panagia at Chavriata and (b) the Church of Agia Marina at Soullaroi.

Table 3: Shear demands based on the Chavriata response spectra in the EastWest (y-y) transverse direction.

\begin{tabular}{|l|c|c|}
\hline Name of church & $\begin{array}{c}\text { Demands on the pier } \\
\boldsymbol{N}_{\boldsymbol{y}}(\mathrm{KN}) / \boldsymbol{M}_{\boldsymbol{y}}(\mathrm{KNm}) / \\
\text { and } \boldsymbol{Q}_{\boldsymbol{y}}(\mathrm{KN})\end{array}$ & $\begin{array}{c}\text { Shear capacity } \boldsymbol{Q}_{\boldsymbol{s l}}(\mathrm{KN}) / \\
\text { against sliding } \boldsymbol{Q}_{\boldsymbol{d g}}(\mathrm{KN}) \\
\text { against diagonal failure }\end{array}$ \\
\hline Agia Marina, Soullaroi & $560 / 325 / \mathbf{1 3 5 1}$ & $864 / \mathbf{6 9 4}(\mathrm{KN})$ \\
\hline Panagia, Chavriata & $1059 / 475 / \mathbf{2 3 3 0}$ & $725 / 779(\mathrm{KN})$ \\
\hline
\end{tabular}


Next, the expert system will be utilised in order to evaluate the performance of the piers of the West walls for both churches that are formed from the door openning. Table 3 lists the more severe demands for these piers in terms of stress resultants $\boldsymbol{N}_{\boldsymbol{y}}, \boldsymbol{M}_{\boldsymbol{y}}$, and $\boldsymbol{Q}_{\boldsymbol{y}}$, as these demands resulted from the numerical analyses with horizontal seismic forces equal to the base shear values listed in table 1 . Together with these demands the shear capacity values of the examined piers are also listed in this table, against sliding and against diagonal failure, as they were found by applying the developed expert system. As can be seen for the piers of both churches the diagonal failure is predicted. Moreover, it can also be seen that the values of the shear capacity/demand ratio based on the values of table 3 are equal to $0.51<1$ for the church of Agia Marina at Soullaroi, and $0.33<1$ for the church of Panagia at Chavriata. Again, through this process of evaluating the performance of the examined piers the shear damage predictions are in agreement with the observed performance.

\section{Conclusions}

1. An expert system was developed to predict the in-plane bearing capacity and the corresponding mode of failure of unreinforced masonry piers subjected to a combination of gravitational loads and horizontal in-plane forces is shown to be reasonably successful.

2. Applying this expert system for predicting the performance of masonry piers of two churches damaged by the recent Kefalonia-Greece 2014 earthquake, good agreement could be found between shear damage predictions and the observed performance.

\section{Dedication}

To the memory of Professor Demosthenes Talaslidis of the Laboratory of Statics and Dynamics of Structures, Department of Civil Engineering, Aristotle University, Thessaloniki, Greece.

\section{References}

[1] Manos G. C. (2011) "Consequences on the urban environment in Greece related to the recent intense earthquake activity", Int. Journal of Civil Engineering and Architecture, Volume 5, No. 12 (Serial No. 49), pp. 10651090.

[2] Provisions of Greek Seismic Code with revisions of seismic zonation", Government Gazette, $\Delta 17 \alpha / 115 / 9 / \Phi N 275$, No. 1154, Athens, 12 Aug. 2003.

[3] Manos G., Soulis V., Felekidou O., Matsou V. (2010) “A Numerical Investigation of the Dynamic and Earthquake Behaviour of Byzantine and Post-Byzantine Basilicas”, 9th U.S. and 10th Canadian Earthq. Eng. Conf., Canada. 
[4] Manos, G.C, Kotoulas, L., Matsou, V., Felekidou, O. "Dynamic behaviour of Greek Post-Byzantine churches with foundation deformability and evaluation of their earthquake performance", CompDyn2013, 12-14 June 2013, Greece.

[5] Manos G.C., Soulis V., Karamitsios N. (2012) "The Performance of PostByzantine churches during the Kozani-1995 Earthquake - Numerical Investigation of their Dynamic and Earthquake Behavior", 15WCEE, Portugal.

[6] Gulkan P., Clough R.W., Manos G.C. and Mayes R.L. (1990) "Seismic Testing of Single-story Masonry Houses : Parts 1 \& 2", Journal of Str. Eng. ASCE, Vol. 116, No 1, January 1990, pp. 235-274.

[7] European Committee for Standardization, Euro-code 6 (2005) "Design of Masonry Structures, Part 1-1: General Rules for Building. Rules for Reinforced and Un-reinforced Masonry”, EN 1996-1-1:2005.

[8] Turnsek V., Cacovic F. (1971) Some experimental results on the strength of brick masonry walls. In: Proceedings of the 2 nd international brick-masonry conference. British Ceramic Society, Stoke-on-Trent, pp. 149-156.

[9] Bernardini A., Modena C., Turnsek V., Vescovi U. (1980) A comparison of three laboratory test methods used to determine the shear resistance of masonry walls" Proc. 7th WCEE, vol 7, IAEE, Istanbul, pp. 181-184.

[10] Tomaževič M. (2009) "Shear resistance of masonry walls and Eurocode 6: shear versus tensile strength of masonry", Materials and Structures, August 2009, Volume 42, Issue 7, pp. 889-907.

[11] Manos G.C. \& Kozikopoulos E. (2015) "The dynamic and earthquake response of Basilica Churches in Kefalonia-Greece including soilfoundation deformability and wall detachment", CompDyn2015, KreteGreece.

[12] Manos G.C., Soulis V., Diagouma A. (2008) "Numerical Investigation of the behaviour of the church of Agia Triada, Drakotrypa, Greece", Journal in Advances in Engineering Software 39, 284-300. 